\title{
A new material for the performance check of X-ray spectrometers attached to a SEM
}

\author{
M. Procop, V.-D. Hodoroaba, M. Griepentrog \\ Bundesanstalt fuer Materialforschung und -pruefung (BAM), D-12200-Berlin, Germany
}

Most of scanning electron microscopes are additionally equipped with an energy dispersive X-ray spectrometer (EDS) and sometimes even with a wavelength dispersive spectrometer (WDS). Although modern instruments have a high reliability, periodical check of the instrument performance is recommended. It is mandatory for test laboratories accredited according to norm ISO 17025.

In case of EDS the performance check usually comprises the calibration of the energy scale, the measurement of the FWHM of the Mn-Ka and C-K lines, and the measurement of the L/K intensity ratio for $\mathrm{Cu}, \mathrm{Ni}$ or $\mathrm{Co}$ to detect a possible contamination of the detector. Recommendations for the measurements are given in the norm ISO 15632.

In case of WDS one is interested in the stability of the peak count rate as a measure for correctness of proportional counter operation, counting gas composition and adjustment of the diffraction crystals.

A set of several specimens is currently used to perform the individual measurements. We propose instead the usage of a single specimen consisting of the five elements carbon, aluminum, manganese, copper and zirconium.

The material proposed has been prepared as a layer on a steel substrate by reactive sputtering of the four metals in an acetylene atmosphere. Thickness of deposited layers is about $10 \mu \mathrm{m}$. FIG. 1 gives a photograph of the specimen. The diameter and thickness of the substrate are 25 and $5 \mathrm{~mm}$, respectively. The specimen can be easily handled by the operator and mounted into the SEM or microprobe. The layer with its Vickers hardness of about 1000 has a good scratch resistance. Long term stability in the laboratory atmosphere and also under electron beam exposure has been intensively tested [1].

FIG. 2 shows a $20 \mathrm{kV}$ X-ray spectrum of the specimen with the $\mathrm{Cu}-\mathrm{K} \alpha$ or $\mathrm{Mn}-\mathrm{K} \alpha$ line for energy calibration, the Al-K line for the case that a second line shall be used for energy calibration, and the $\mathrm{Cu}-\mathrm{L}$ line for the $\mathrm{Cu} \mathrm{L} / \mathrm{K}$ ration calculation. Also the FWHM of $\mathrm{Mn}-\mathrm{K} \alpha$ can be found from the 20 $\mathrm{kV}$ spectrum, whereas the FWHM for the C-K line should be taken at $10 \mathrm{kV}$. The number of intensive lines is increased from 9 to 11 in a $30 \mathrm{kV}$ spectrum due to the appearance of $\mathrm{Zr}-\mathrm{K} \alpha$ and $\mathrm{Zr}$ $\mathrm{K} \beta$. This makes the specimen a candidate for the linearity check of the pulse processor as recommended in ANSI/IEEE 759.

Line energies are well positioned to check the crystals typically used for the WDS: C-K, Mn-L and $\mathrm{Cu}-\mathrm{L}$ for multilayers, Al-K for TAP, $\mathrm{Zr}-\mathrm{L} \alpha$ for PET and finally $\mathrm{Mn}-\mathrm{K} \alpha$ and $\mathrm{Cu} \mathrm{K} \alpha$ for $\mathrm{LiF}$.

Specimens are available from BAM on request.

The research was funded by the Measurement \& Testing Activity of the European Community's 5th Framework "Growth" Programme (EC-Research Directorate General) Contract No. G6RD-CT2002-00851.

References

[1] M. Alvisi et al., Book of Abstracts of $9^{\text {th }}$ European Workshop on Modern Developments and Applications in Microbeam Analysis, Florence, Italy, 2005, 189 (submitted to Microsc. Microanal.). 

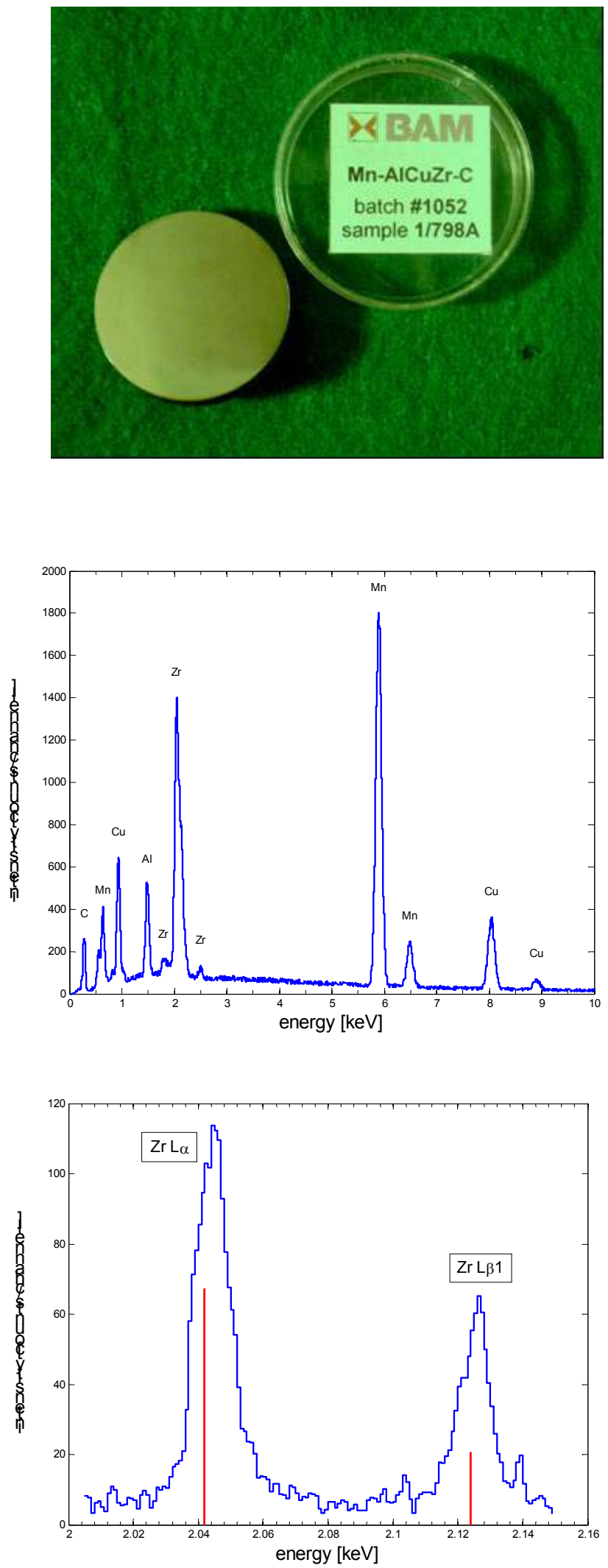

FIG. 1. Photograph of the proposed specimen for spectrometer check
FIG. 2. $20 \mathrm{kV}$ X-ray spectrum of the proposed material for spectrometer performance check
FIG. 3. $20 \mathrm{kV} \mathrm{Zr-L} \mathrm{spectrum} \mathrm{measured}$ with a parallel beam WDS 